
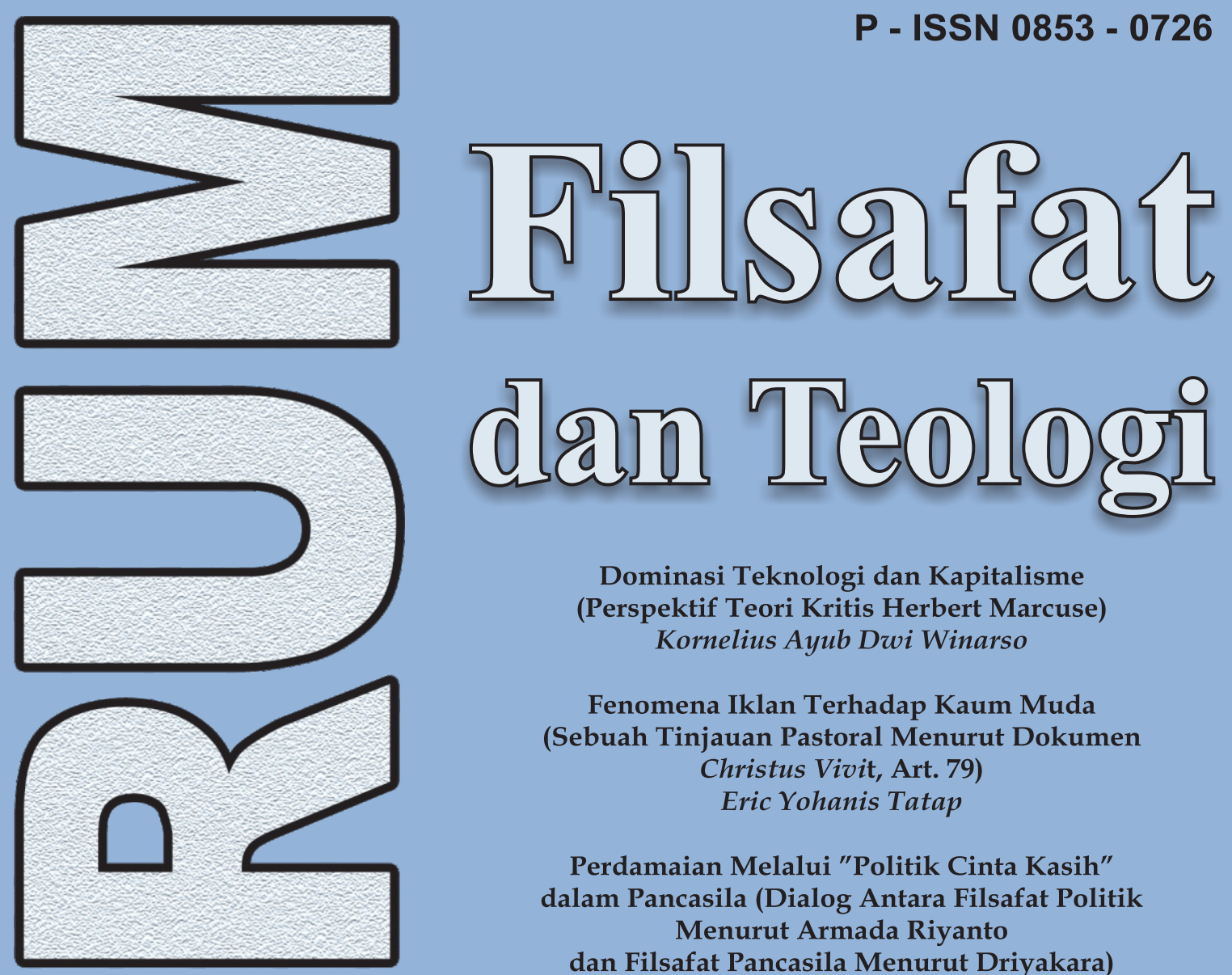

Dominasi Teknologi dan Kapitalisme (Perspektif Teori Kritis Herbert Marcuse) Kornelius Ayub Dwi Winarso

Fenomena Iklan Terhadap Kaum Muda (Sebuah Tinjauan Pastoral Menurut Dokumen Christus Vivit, Art. 79)

Eric Yohanis Tatap

Perdamaian Melalui "Politik Cinta Kasih" dalam Pancasila (Dialog Antara Filsafat Politik Menurut Armada Riyanto dan Filsafat Pancasila Menurut Driyakara) Thomas Onggo Sumaryanto

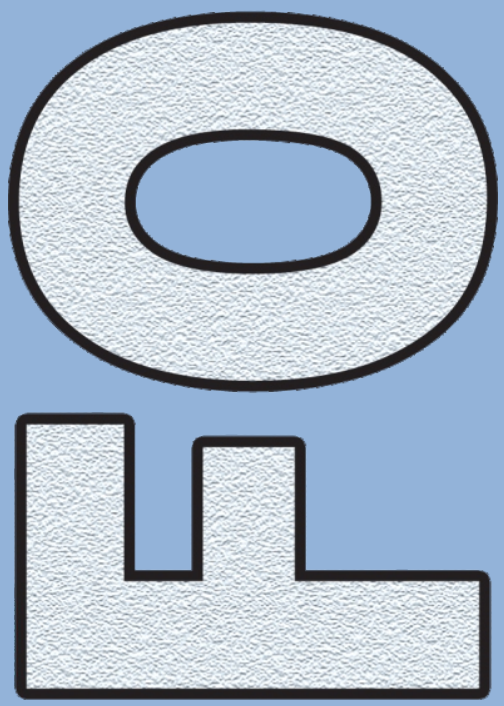

Kebahagiaan dalam Ruang Keseharian Manusia Yakobus Banusu \& Antonius Denny Firmanto

Kesadaran dan Kepedulian Ekologis Budaya dalam Upacara Mangokal Holi Juli Antonius Sihotang

Spiritualitas Imamat dalam Bayang-bayang Tantangan Pastoral

Emanuel Richardus Buang Lela E Edison R.L. Tinambunan

Imam Pelayanan Sabda: Perspektif Spiritualitas Imamat Hironimus Edison E Edison R.L. Tinambunan $* * * * *$

\title{
TELAAH BUKU
}




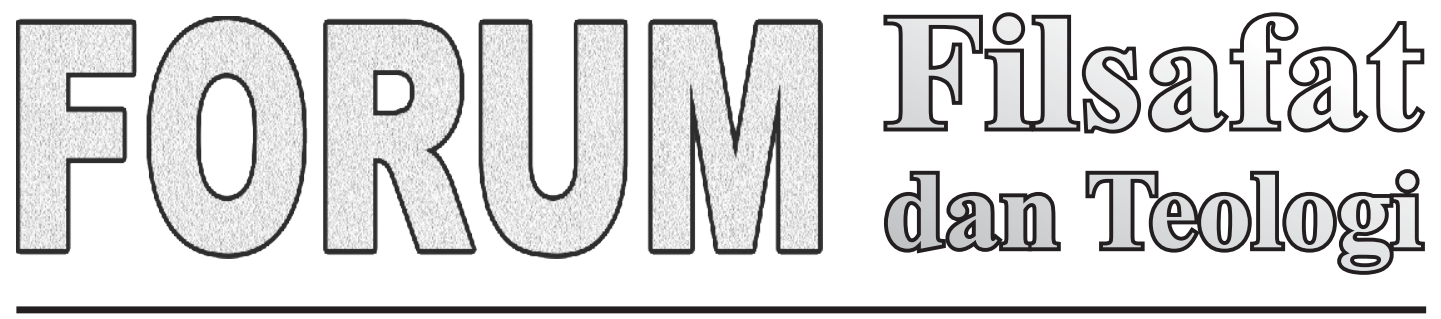

P-ISSN 0853 - 0726

FORUM is a scientific journal that aims to become a forum for new ways of doing theology and philosophy and for philosophical and theological thinking in general for students of philosophy and theology and academics and the wider community.

FORUM was founded in 1979 and is a scientific journal that elaborates philosophical and theological reflections with a multidisciplinary approach. This journal is published by STFT WidyaSasana and is published twice a year.

FORUM invites students, academics and anyone to make philosophical and theological contributions the humanities study in order to realize a life that is faithful, humanist and tolerant. Articles that are reviewed peer support and realize the new way of doing theology and philosophy. It is therefore important to agree on standards of expected ethical behavior for all parties involved in the act of publishing: authors, journal editors, peer reviewers, publishers and the public.

\section{FOCUS AND SCOPE:}

FORUM focuses on philosophical and theological studies based on library studies and field research. Philosophical and theological reflections should present a systematic effort to explore new ways of doing philosophy and theology.f traditions.

\section{PUBLISHER :}

P3M Sekolah Tinggi Filsafat Teologi

Widya Sasana Malang

J1. Terusan Rajabasa 2,

Malang 65146 Indonesia

Telp. 0341 - 552120

Fax. 0341 - 566676

Email : forum_stftws@yahoo.com

Website : http://www.forumstftws.org

\section{Editor in Chief}

HendricusPidyartoGunawan; (Google Scholar; h-index: 2); WidyaSasana College of Philosophy Theology, Malang. (Editor-inChief).

\section{Managing Editors}

Valentinus Saeng; (Google Scholar; h-index: 2); WidyaSasana College of Philosophy Theology, Malang.

Gregorius Tri Wardoyo; (Google Scholar; h-index: ); WidyaSasana College of Philosophy Theology, Malang.

\section{Editorial Board}

Pius Pandor; (Google Scholar; h-index: 2); Widya Sasana College of Philosophy Theology, Malang.

Robert Pius Manik; (Google Scholar; h-index: ); Widya Sasana College of Philosophy Theology, Malang.

Benny Phang; (Google Scholar; h-index: ); Widya Sasana College of Philosophy Theology, Malang.

William Chang; (Google Scholar; h-index: 5); Widya Darma University, Pontianak.

Kristianus Atok; (Google Scholar; h-index: 3); STAKATN,

Matias Daven; (Google Scholar; h-index: 1); STFK Ledalero.

Agustinus Wisnu Dewantara; (Google Scholar; h-index: 13); Widya Yuwana University, Madiun.

Carolus Borromeus Mulyatno; (Google Scholar; h-index: 4); Sanata Dharma University, Yogyakarta.

Laurentius Tinambunan: (Google Scholar; h-index:); STFT Pematang Siantar.

Muji Kartika Rahayu; (Google Scholar; h-index: 4); Brawijaya University, Malang.

Nikasius Jatmiko; (Google Scholar; h-index: 2); Parahyangan University, Bandung.

Shelomita Selamat; (Google Scholar; h-index:); Santi Buana Institute, Bengkayang - Kalimantan Barat.

Dr. I Ketut Gegel; (Google Scholar; h-index: 1); Widya Sasana College of Philosophy Theology, Malang.

\section{English Language Advisor}

Odilia Rahayu Widji Astuti

Indonesian Language Advisor

Edison R.L. Tinambunan

Information and Technology

Imilda Retno Arum Sari 


\section{Author Guidelines}

1. Article must have between 100 and 150 words abstract in English and Indonesian with four or five keywords.

2. Article should be between 4,000 and 7,000 words, included references and footnotes.

3. Article must be a study base on either literature (text) or field research.

4. Article should be submitted in Word (single-spaced and 12-point font).

5. Please be noted that Forum allows quotation from classic languages in Latin only; any other quotations in Greek, Hebrew, Arabic etc., and any symbol characters are not permitted.

6. Heading:

- First-level headings (e.g. Introduction, Conclusion) should be in bold with a capital letter for any proper nouns and words other than articles.

- Second-level headings should be in bold italics with a capital letter for any proper nouns and words other than articles.

- Third-level headings should be in italics with a capital letter for any proper nouns and words other than articles.

7. Footnote and Bibliography (see to Turabian Style).

8. The article submitted will be peer-reviewed by qualified academics; this process may take weeks or months. All submitted papers are subject to review of the editors, editorial board, and reviewers.

9. The author should be willing to respond questions from the readers of his/her article; in case there is corrections, the author must revise the article as soon as possible.

\section{Guidelines for book reviews}

1. Please include, at the beginning: Author, Title, Place, Publisher, Date, number of pages, ISBN of the book reviewed.

E.g., Taylor, Charles. A Secular Age. Cambridge: The Belknap Press of Harvard University Press, 2007. 874+x pp. ISBN-13:978-0-674-02676-6.

2. The review begin with abstract, three or four keywords and continue with a brief overall description of the book.

3. The review may include:

- The content and its complexity of the book.

- Comments on the author's style and contribution of the book.

- Philosophical or theological methodology of presentation.

- Position of the philosophical or theological arguments in its field.

4. The preferred format for submissions is MS-Word.

5. Review should be about 1500 words long. The name, affiliation and email address of the reviewer should appear at the end of the review. 


\title{
SPIRITUALITAS IMAMAT DALAM BAYANG- BAYANG TANTANGAN PASTORAL (Imam sebagai Pelayan dalam Tantangan Pastoral di Keuskupan Timika)
}

\author{
Emanuel Richardus Buang Lela dan Edison R.L. Tinambunan \\ Mahasiswa Program Magister dan Dosen STFT Widya Sasana Malang \\ manuelrichardo93@gmail.comE edisontinambunan@gmail.com
}

\begin{abstract}
:
This article focuses on reflections of the priestly vocation as a minister in the context and pastoral situation in the Diocese of Timika. The approach is studyingon ecclesiastical documents in regarding on the priesthood spirituality in serving of God's people. The purpose of this paper is to discover the high spirit of ministry of a priest who is based on the example of Jesus Christ as Teacher and Chief Pastor in the pastoral ministry of the TimikaDiocese. Total service in dedicative involvement, a soothing presence, entering into the struggles of family life, and having the courage of dialoguing with anyone are a concrete service to realize the spirit of the ministry of Jesus Christ in the challenges of the pastoral field in the Timika Diocese.
\end{abstract}

Keywords: priesthood spirituality, ministry, pastoral challenges, church documents, Timika diocese.

\begin{abstract}
Abstrak
Artikel ini berfokus pada refleksi mengenai panggilan hidup imamat sebagai pelayan di tengah konteks dan situasi pastoral di Keuskupan Timika. Pendekatan yang digunakan adalah studi dokumen gerejani mengenai spiritualitas imamat dalam pelayanan bagi umat Allah. Tujuan dari tulisan ini adalah untuk menemukan semangat pelayanan yang luhur dari seorang imam yang bertolak pada teladan Yesus Kristus sebagai guru dan gembala utama dalam pelayanan pastoral di keuskupan Timika. Pelayanan yang total dalam keterlibatan yang dedikatif, kehadiran yang menyejukkan, masuk dalam pergumulan hidup keluarga, dan berani untuk berdialog dengan siapa pun merupakan pelayanan konkret demi mewujudkan spirit pelayanan Yesus Kristus di tengah tantangan medan pastoral di Keuskupan Timika.
\end{abstract}

Kata Kunci: spiritualitas imamat, pelayanan, tantangan pastoral, dokumen gereja, keuskupan Timika. 


\section{Pengantar}

Hakikat dan tujuan dari Sakramen Imamat adalah untuk dan demi pelayanan. Seorang imam dipanggil dari dunia dan diberikan kembali kepada dunia semata-mata demi pelayanan. Ia ditahbiskan dan diberikan anugerah Sakramen Imamat agar semua orang yang ia layani memperoleh keselamatan saat ini (hic et nunc) dan di masa yang akan datang. Dalam masa-masa inilah ia berperan sebagai alter Kristus untuk melanjutkan misi keselamatan Allah di tengah dunia. Seperti Yesus, para imam menghadirkan peran ministerial dalam seluruh karya dan kehidupannya di mana dan ke mana saja ia diutus oleh Kristus dan Gereja-Nya. Dalam menjalani tugas dan peran ministerial ini, seorang imam ditantang untuk senantiasa menghadirkan spirit Kristus dalam keseluruhan pelayanan dan penggembalaannya seperti Kristus sendiri, "Aku datang, supaya mereka mempunyai hidup, dan mempunyai dalam segala kelimpahan" (Yoh 10:10). Spirit Yesus ini hendaknya menjadi bagian dari kehidupan imamat seorang imam yang siap untuk memberikan kehidupan dan kelimpahan di dalam Kristus bagi umat Allah yang dipercayakan kepadanya.

Misi yang sangat penting ini mesti diwujudkan dalam hidup imamat seorang imam. Dalam konteks ladang misi di wilayah Keuskupan Timika, misi evangelisasi yang terwujud dalam imamat ministerial seorang imam merupakan spirit yang penting dan mendesak untuk diwujudkan. Gereja Keuskupan Timika yang masih sangat muda, medan yang sangat luas, dan tantangan sosial budaya yang tidak mudah membuat misi evangelisasi sering kali terhambat. Sadar atau tidak sadar, situasi-situasi pelik di ladang misi ini sangat memengaruhi pola hidup imamat seorang imam dan spiritualitas pelayanan yang dihayatinya. Artikel ini merupakan refleksi yang didasarkan pada dokumen-dokumen gerejani mengenai pelayanan imam dalam konteks ladang misi di Keuskupan Timika.

\section{Imam sebagai Pelayan}

Seorang imam dan imamatnya tidak bisa dipisahkan dengan sosial kultur yang sedang berlangsung di masyarakat, karena ia baik di dalam hidup maupun pelaksanaan tanggung jawab pasti berhadapan dengan dunia untuk berkontak. ${ }^{1}$ Ketika berkontak dengan sosial-kultur dalam masyarakat setempat, seorang imam juga akan terhubung dengan realitas kehidupan masyarakat setempat. Dengan demikian, ia terlibat dan turut merasakan sukaduka, kecemasan dan kegembiraan, serta harapan dan tantangan dalam kehidupan masyarakat di tempat ia diutus. Dalam situasi dan kondisi inilah imam mewujudkan misi evangelisasi yang konkret dan berdaya guna bagi

1 Edison R.L. Tinambunan, “Quo Vadis Imam - Imamat Revolusi Industri 4.0," Siapakah Manusia; Siapakah Allah, Vol. 29, 28 (Oktober 2019), 320. 
keselamatan jiwa-jiwa yang dipercayakan kepadanya. Pada saat inilah imamat ministerial di dalam dirinya dapat diwujudnyatakan. Untuk itu, dalam tulisan ini ditampilkan beberapa dokumen Gereja yang mendasari spirit pelayanan seorang imam. Berikut ini beberapa dokumen Gereja yang secara spesifik membahas dasar-dasar dan hakikat imam sebagai seorang pelayan dalam menjalani hidup imamatnya.

Dokumen Gereja yang secara spesifik membahas pelayanan imam di tengah umat dan dunia adalah Presbyterorum Ordinis. Dekrit ini mengangkat peran imam dan tujuan seorang imam ditahbiskan bagi Allah. Seperti Kristus yang diutus ke tengah dunia dan menjadi sama seperti manusia, begitu pula seorang imam ditahbiskan menjadi in Persona Christi juga tampil di tengah dunia dan tidak terpisah dari sesamanya, walaupun ia disendirikan untuk Injil Allah. Oleh karena itu, dokumen menegaskan bahwa,

“Karena panggilan dan tahbisan mereka, para imam Perjanjian Baru dalam arti tertentu disendirikan dalam pengakuan Umat Allah, tetapi bukan untuk dipisahkan dari umat atau dari sesama mana pun juga, melainkan sepenuhnya ditakdiskan bagi karya, yakni tujuan, mengapa Tuhan memanggil mereka. Mereka tidak akan mampu menjadi pelayan Kristus, seandainya mereka tidak menjadi saksi dan pembagi kehidupan lain daripada yang lain di dunia ini." ${ }^{2}$

Lebih lanjut Gereja menegaskan sekaligus mengingatkan para imamnya bahwa seluruh pelayanan imam baik pelayanan sakramental dan pastoral mesti bermuara dan bersumber dari pelayanan Ekaristi. Seorang imam sebagai in Persona Christi hendaknya bertindak sebagai pelayan Dia ketika merayakan Sakramen Ekaristi. Inilah kekhasan pelayanan seorang imam. Ia tidak bertindak sebagai pelayan biasa seperti profesi-profesi duniawi lainnya, melainkan pelayan yang keseluruhan hidupnya bertumpu dan bertolak dari imamat Kristus yang terwujud dalam Perayaan Ekaristi. Dalam Imamat Kristus terwujud pelayanan yang utuh dan total bagi keselamatan seluruh umat manusia.

“Dengan Sakramen Baptis, para imam mengantar orang-orang masuk menjadi anggota Umat Allah. Dengan Sakramen Tobat, mereka mendamaikan para pendosa dengan Allah dan dengan Gereja. Dengan Sakramen Pengurapan Orang Sakit, mereka meringankan para penderita penyakit. Terutama dengan merayakan Misa mereka mempersembahkan kurban Kristus secara sakramental. Dengan demikian, sakramen-sakramen lainnya, begitu pula semua pelayanan gerejawi serta karya kerasulan, berhubungan erat dengan Ekaristi dan terarahkan kepadanya. Sebab dalam Ekaristi Suci tercakuplah seluruh kekayaan rohani Gereja, yakni Kristus sendiri." ${ }^{3}$

Dokumen ini juga merumuskan secara jelas peran dan tanggung jawab imam sebagai seorang pemimpin bagi umat Allah yang dipercayakan

2 Presbyterorum Ordinis, Penerjemah R. Hardawiryana (Jakarta: Dokpen KWI, 2009), no. 3. Untuk selanjutnya akan disingkat dengan PO diikuti nomor.

3 PO.5. 
kepadanya. Dalam reksa pastoralnya, hakikat seorang imam sebagai pemimpin bukan terwujud dalam kehidupan yang hanya ingin dilayani, namun senantiasa melayani umat Allah. Hal ini sesuai dengan perannya sebagai in Persona Christi atau alterChristus yang adalah Kepala dan Gembala. Oleh karena itu, para imam diingatkan agar mengikuti teladan Tuhan, dalam membangun Gereja. Hendaknya,

\begin{abstract}
"Para imam harus bergaul dengan semua orang penuh perikemanusiaan. Janganlah mereka bertindak terhadap mereka seturut selera orang-orang, melainkan menurut tuntutan-tuntutan ajaran dan hidup Kristen, dengan mengajar serta memperingatkan mereka juga sebagai putra-putri yang terkasih, menurut pesan Rasul, 'Siap-sedialah, entah baik atau tidak baik waktunya, nyatakanlah apa yang salah, tegurlah dan nasihatilah dengan segala kesabaran dan pengajaran' (2Tim $4: 2) .{ }^{4}$
\end{abstract}

Lebih dari itu, Gereja senantiasa mengingatkan imamnya untuk terusmenerus berada di pihak orang miskin dan bertanggung jawab atas mereka. Para imam juga diingatkan untuk tetap memperhatikan generasi muda, para suami-istri dan orang tua, serta mereka yang sakit dan menjelang ajal. Inilah teladan yang diberikan oleh Tuhan sendiri untuk imamnya dalam pewartaan Injil dan karya keselamatan di tengah dunia. Inilah misi evangelisasi yang mesti diwartakan senantiasa oleh para imam di tengah dunia saat ini. Pada akhirnya, dokumen meneguhkan para imam dalam semangat pelayanan di tengah dunia, "Dunia sekarang ini dipercayakan kepada cinta kasih dan pelayanan para Gembala Gereja, hendaknya dalam berkarya mereka tidak pernah seorang diri, melainkan bertumpu pada kekuatan Allah yang mahakuasa." ${ }^{5}$

Dokumen selanjutnya tentang imamat ministerial adalah Pastores Dabo Vobis. Dokumen ini merupakan dokumen yang paling banyak berbicara tentang imam pasca-Konsili Vatikan II. Sifat dari dokumen ini juga sangat relevan dengan kehidupan imam di milenium kedua. Isi dokumen ini tidak hanya mengenai pola formasi calon imam, namun juga pelayanan imam, dan pembinaan berkelanjutan para imam, khususnya mengenai bentuk dan karakter pelayanan yang bersatu dengan Kristus sebagai Kepala dan Gembala di tengah hidup pastoralnya.

Dokumen Pastores Dabo Vobis menegaskan hakikat imamat ministerial seorang imam bahwa hubungan imam dengan Kristus, dan dalam Dia dengan Gereja-Nya, terdapat pada kenyataan pribadi imam, berdasarkan pengudusan / pengurapannya secara sakramental, dan dalam kegiatannya, artinya: dalam misi atau pelayanannya. Imam sebagai pelayan mengabdi kepada Kristus yang hadir dalam Gereja sebagai misteri, persekutuan, dan perutusan, "Imam itu hamba Gereja sebagai persekutuan, karena dalam persekutuan dengan Uskup

4 PO.6.

5 PO. 22. 
serta hubungan erat dengan para imam dan kesatuan dengan jemaat dalam keselarasan dengan panggilan, karisma, dan pelayanan." ${ }^{\prime 6}$

Gagasan penting mengenai tugas pelayanan imam bagi umat Allah kembali dipertegas oleh PDV bahwa,

"Peranan maupun tugas imam dalam Gereja tidak menggantikan, melainkan mendukung imamat baptisan (umum). Maka imam mempunyai hubungan positif membantu kaum awam. Tugas imam yakni melayani iman, harapan, dan kasih umat awam. Sebagai saudara dan sahabat, ia mengakui dan menegakkan martabat umat awam sebagai putra-putri Allah."7

Gagasan ini adalah sangat penting untuk menjadi patokan kedekatan antara imam dan kaum awam. Kedekatan antara imam dan kaum awam mesti dilandasi oleh spirit persaudaraan dan persahabatan. Dengan kedekatan ini, pelayanan imam bagi umat dapat mudah diterima. Tentu saja hal ini akan menjadi sulit apabila seorang imam menaruh jarak yang jauh dengan umat. Dengan semangat persaudaraan dan persahabatan seorang imam dapat dengan mudah untuk hadir dan terlibat dalam keseluruhan keprihatinan hidup umat Allah yang dilayani.

Lebih lanjut, PDV banyak berbicara mengenai pembinaan berkelanjutan para imam. Dalam dimensi ini, melalui PDV, Gereja tetap mengingatkan imamnya untuk menghadirkan pelayanannya yang intim dan total bagi umat Allah. PDV secara khusus mengingatkan dan mengharapkan para imam untuk menghayati spirit kehadiran dan keterlibatannya dalam kehidupan pastoralnya dalam aspek manusiawi. Dikatakan bahwa imam mesti terlibat, tanggap, dan mampu menangkap persoalan-persoalan yang tidak mampu diungkapkan oleh umat. Mereka juga mesti ikut merasakan harapan dan dambaan, kegembiraan serta beban hidup umat. Dengan demikian ia dapat menjumpai semua orang dalam dialog dengan mereka. Ia juga dapat mengenal dan ikut merasakan serta menanggung beban hidup dari kemiskinan hingga penyakit, dari penolakan hingga kebodohan, kesepian, dan kemiskinan materiil dan moril dan menjadikannya semakin autentik serta nyata melalui kasihnya terhadap sesama. ${ }^{8}$ Kiranya aspek inilah yang mesti terus-menerus terungkap dalam kehidupan imamat seorang imam. Inilah yang menjadi harapan umat dari gembalanya. Sementara itu, secara terus-menerus ia juga membuka diri untuk menerima cinta kasih pastoral Yesus Kristus. Dengan anugerah itu ia didorong dan disemangati untuk makin menyelami situasi nyata sesama dalam perutusannya.

6 Yohanes Paulus II, Pastores Dabo Vobis, penerjemah R. Hardawiryana (Jakarta: Dokpen KWI, 1992), artikel. 16. Untuk selanjutnya akan disingkat dengan PDV diikuti dengan nomor artikel.

7 PDV. 17.

8 PDV. 72. 
Berkaitan dengan perutusan pastoral ini, dokumen dengan judul The Priest Pastor and Leader of the Parish Community mengajak para imam untuk menyadari identitasnya sebagai seorang gembala di paroki. Melalui paroki, imam mewujudkan misi perutusannya sebagai seorang pelayan yang penuh dedikasi dan tanggung jawab. Paroki adalah lembaga Gereja yang paling nyata hadir di tengah komunitas umat beriman. Paroki merupakan bentuk kehadiran Gereja di tengah dunia. Dengan kehadirannya, dimaksudkan sekaligus hidup dan menyelenggarakan tugas perutusan penebusan yang direalisasikan dalam pelayanan sakramen dan pelayanan-pelayanan kasih yang lain. Mengingat "wujud" kehadiran yang demikian, paroki membutuhkan "unit administrasi" untuk pembangunan dan pengembangannya. Di dalam paroki, Gereja sebagai Tubuh Mistik Kristus tampak nyata. Tubuh Mistik Kristus tersebut terorganisir dalam sistem kepemimpinan dan terwujud dalam berbagai dinamika paroki. Di dalam paroki inilah seorang imam adalah penyuluh bagi umat Allah yang dipimpin olehnya. "Bagi sebagian besar umat Katolik, paroki adalah pengalaman utama mereka di Gereja. Di sinilah mereka berkumpul untuk ibadat mingguan, merayakan momen yang paling membahagiakan, dan berduka atas kehilangan terdalam mereka. Paroki adalah bagian penting dari kehidupan umat Katolik." ${ }^{9}$ Oleh karena itu, imam yang berkarya di paroki melaksanakan bukan hanya pelayanan di bidang liturgi, melainkan juga pelayanan yang total dan ikhlas bagi reksa jiwa-jiwa yang dipercayakan kepadanya. "Dia adalah hamba Kristus. Melalui Dia, dengan Dia, dan di dalam Dia, imam menjadi hamba umat manusia. Keberadaannya, secara ontologis berasimilasi dengan Kristus dan merupakan dasar dari penahbisan untuk pelayanan komunitas."10

Selain itu, dokumen ini juga mengajak para imam yang bertugas di paroki (pastor paroki) untuk terus-menerus menghidupkan kekudusan di dalam paroki. Namun demikian, pastor paroki sebaiknya tidak meninggalkan reksa pastoral dan komitmennya dalam pergumulan hidup sosial umatnya. Ia senantiasa hadir dalam hidup iman umat dan juga pergumulan nyata umat di tengah dunia.

“Promosi pastoral yang benar dari kekudusan komunitas paroki kita menyiratkan pengajaran otentik tentang doa, katekese yang diperbarui, persuasif dan efektif tentang pentingnya hari Minggu dan perayaan harian Ekaristi Maha Kudus, tentang komunitas dan adorasi pribadi Sakramen Maha Kudus, pada praktik Sakramen Tobat, pada arahan spiritual, pada devosi Maria, pada teladan para Orang Kudus, serta pada komitmen apostolik yang diperbarui untuk menjalankan tugas seharihari komunitas dan individu, reksa pastoral yang tepat keluarga, dan keterlibatan politik dan sosial yang konsisten." 11

9 Bdk. Robert J. Hater, The Catholic Parish: Hope for a Changing World, (New Jersey: Paulist Press, 2004), 22.

10 The Priest Pastor and Leader of the Parish Community, (2002), 5.

11 The Priest Pastor and Leader of the Parish Community, (2002), 27. 


\section{Imam di Tengah Tantangan Pelayanan: Konteks Pastoral di Wilayah Keuskupan Timika}

Luas wilayah Keuskupan Timika kurang-lebih 102,892 km². Terbentang dari pantai selatan yang berbatasan dengan Laut Arafura, naik ke bagian barat Pegunungan Tengah Papua, dan turun ke bagian utara Teluk Cenderawasih yang meliputi Kepulauan Yapen, Biak, dan Supiori, yang berbatasan dengan Samudera Pasifik.

Kondisi alam di seluruh wilayah keuskupan pun bervariasi. Bagian utara dan selatan merupakan dataran rendah yang didominasi oleh hutan hujan tropis yang padat serta sungai-sungai yang besar. Sepanjang muara sungaisungai terdapat rawa-rawa yang ditumbuhi berbagai jenis pohon, terutama bakau dan sagu. Hutan, rawa-rawa dan muara-muara sungai inilah yang merupakan tempat masyarakat lokal menggantungkan hidupnya. Beberapa suku di wilayah ini masih hidup sebagai semi-nomade. Mereka berpindahpindah antara hutan sagu, muara sungai, kampung, dan menggantungkan hidup pada kemurahan alam. ${ }^{12}$

Wilayah dataran tinggi merupakan barisan pegunungan tengah Papua dengan puncak tertinggi adalah Jayawijaya $(4.880 \mathrm{~m}$.) yang diselimuti salju abadi. Suku-suku di wilayah dataran tinggi umumnya menetap di kampungkampung. Mereka bercocok tanam atau memelihara ternak untuk memenuhi kebutuhan hidup mereka. Kampung-kampung mereka terletak di antara 1500 sampai $3000 \mathrm{~m}$., dengan suhu udara yang sangat dingin. ${ }^{13}$

Untuk komposisi umat sendiri, menurut sensus penduduk pada tahun $2020^{14}$, Propinsi Papua memiliki jumlah penduduk sebanyak 3.435.430 jiwa. Jumlah itu dibagi menurut gender dengan perincian sebanyak 1.802.213 lakilaki dan 1.633.217 perempuan. Dari jumlah itu, 1.367.246 jiwa mendiami wilayah pemerintahan tiga belas kabupaten dalam wilayah pelayanan Keuskupan Timika, yang di dalamnya termasuk jumlah umat Katolik sebanyak 113.420 jiwa. $^{15}$

Umat Katolik Keuskupan Timika hidup dan berkembang dalam berbagai suku dan budaya yang tersebar di seluruh wilayah Keuskupan. Berbagai ragam suku bangsa dan budaya meliputi dua belas etnis asli Papua yang terdiri dari: Amungme, Kamoro, Mee, Moni, Dani, Damal, Moor, Nduga, Biak, Numfor, Waropen, dan Yapen. Etnis-etnis asli Papua tesebut hidup, berbaur,

12 Bdk. Dominikus D. Hodo, “Bias Sinar Konsili Vatikan II dalam Implikasi Pastoral di Keuskupan Timika," dalam Mozaik Gereja Katolik Indonesia Tahun Pasca Konsili Vatikan II, eds. Indra V. Sanjaya (Yogyakarta: Kanisius, 2013), 635.

13 Ibid., 636.

14 Bdk.https://papua.bps.go.id/dynamictable/2018/05/16/134/jumlah-penduduk-hasil-proyeksi-menurutjenis-kelamin-dan-kabupaten-kota-di-provinsi-papua-2010-2020.html, diakses 28 November 2020.

15 Jumlah umat per 2015. 
berkembang dalam tatanan sosial secara bersama dengan suku bangsa dan budaya dari luar Papua seperti: Kei, Tanimbar, Flores, Manado, Toraja, Jawa, Batak, dll. Semua suku bangsa dan budaya itu hidup dalam komunitaskomunitas tunggal maupun plural di kota-kota, desa-desa, yang tersebar di wilayah pegunungan, pesisir pantai, lembah-lembah yang membentang luas. ${ }^{16}$

Situasi Keuskupan Timika juga diwarnai oleh beberapa realitas hidup. Realitas-realitas ini merupakan representasi dari berbagai persoalan yang menjadi keprihatinan pastoral di Keuskupan Timika. Sudah sejak lama, keuskupan-keuskupan di Papua bergumul dengan persoalan ketidakadilan hingga persoalan Hak Asasi Manusia (HAM) berat. Dalam hal ini, Gereja berjuang untuk menjadi corong keselamatan bagi domba-domba yang tidak dapat bersuara atas ketidakadilan yang dialami. Sejak wilayah Keuskupan Timika masih bersatu dengan Keuskupan Jayapura, Gereja Keuskupan Jayapura sudah banyak berjuang demi kemanusiaan yang adil dan beradab di Tanah Misi yang sangat luas. ${ }^{17}$

Setelah dimekarkan menjadi sebuah keuskupan baru yang digembalai oleh Mgr. John Philip Saklil, perhatian atas persoalan-persoalan ketidakadilan dan kemanusiaan tidak pernah luput dari perhatian Gereja Katolik Keuskupan Timika. Dengan moto, "Parate Viam Domini", Gereja Keuskupan Timika dengan berbagai upaya mencoba mempersiapkan jalan Tuhan dengan hadir dalam misi kemanusiaan di tengah masyarakat dan mendampingi para korban ketidakadilan. Tantangan medan pastoral, umat dari berbagai latar belakang suku dan bahasa, dan berbagai konflik vertikal dan horizontal yang sering kali terjadi, memanggil Gereja Keuskupan Timika untuk menyuarakan seruan kenabian dengan berbagai cara. Tidak jarang pula situasi sosial, politik, ekonomi, dan pertahanan dan keamanan (hankam) turut memperkeruh keadaan di wilayah pastoral Keuskupan Timika. Situasi-situasi seperti inilah yang kerap menghiasi pergumulan hidup Gereja di Keuskupan Timika. Tidak jarang dari situasi-situasi inilah lahir berbagai ketimpangan dan ketidakadilan sosial yang berujung pada kekerasan, kerusuhan, dan korban jiwa. ${ }^{18}$

Krisis pangan yang terjadi saat ini tampak dalam perubahan iklim, rendahnya produksi bahan pangan, kerusakan sumber-sumber pangan, hilangnya sumber-sumber hayati, habisnya sumber daya alam, munculnya penyakit dan gizi buruk, dan semakin dalamnya jurang antara si kaya dan si miskin. Di lain pihak, kebijakan pemerintah tidak memihak masyarakat pemilik hak ulayat. Masyarakat pemilik hak ulayat mengalami ketidakseimbangan karena terdapat dominasi yang kuat dari pemerintah dan investor serta meningkatnya arus penduduk dari luar yang pada umumnya

16 Op. Cit., 640.

17 Bdk. A. Eddy Kristianto, Menjadi Gereja yang Berjalan Bersama Papua, (Jakarta: OBOR, 2017), 137-143.

18 Bdk. Biru Kira, Berlayar ke Timur, (Yogyakarta: Kanisius, 2014), 27-29. 
menguasai sumber-sumber hak ekonomi masyarakat lokal.Persoalan-persoalan ini kebanyakan dialami di wilayah paroki-paroki di pedalaman. ${ }^{19}$

Persoalan-persoalan kemanusiaan ini merasuk masuk dalam dunia pendidikan. Kualitas pendidikan di pedalaman Papua sungguh memprihatinkan. Gambaran pendidikan yang miris ini berada di kantong-kantong umat Katolik di pedalaman. Berhadapan dengan situasi ini, sepertinya para misionaris awal sudah mempertimbangkannya dengan sangat matang, sehingga ketika mereka mendirikan paroki selalu dibarengi dengan pendirian sekolah dan asrama untuk orang-orang Papua pedalaman yang tinggal jauh dari akses jalan. Oleh karena itu, setiap paroki di pedalaman bertanggung jawab atas sekolahnya dan semua sekolah tersebut bernaung di bawah payung Yayasan Pendidikan dan Persekolahan Katolik (YPPK) keuskupan. Sekolah tidak hanya mengajarkan perihal pengetahuan semata, tetapi juga dibarengi dengan pendidikan moral dan iman yang kuat, sehingga tidak jarang impactyang dihasilkan sungguh-sungguh berkualitas, bahkan ada yang memilih untuk menjadi imam dan biarawan-biarawati.

Persoalan saat ini adalah sekolah-sekolah Katolik yang dahulu terkenal dengan kualitasnya dan menghasilkan impactyang luar biasa, kini menjadi tinggal kenangan. Sekolah-sekolah Katolik dan paroki yang mengawasinya mengalami persoalan biaya operasional sekolah dan kekurangan guru berkualitas yang setia di kampung-kampung untuk mendidik anak-anak setempat. Sekolah-sekolah negeri yang sangat diharapkan karena memiliki kekuatan finansial yang mumpuni juga tidak dapat menaikkan kualitas pendidikan di daerah-daerah pedalaman. Banyak kasus yang terjadi, dana dari pemerintah tidak dikontrol dan dievaluasi secara baik, sehingga banyak dimanfaatkan oleh oknum-oknum tertentu untuk memperkaya diri sendiri. Inilah alasan utama para siswa lulusan sekolah di pedalaman mengalami kesulitan ketika harus melanjutkan pendidikan di kota. ${ }^{20}$

Kondisi pendidikan seperti ini membuat umat beriman tidak dapat kritis terhadap situasi hidup yang menjeratnya. Sekalipun, mereka dapat berpikir kritis, pasti mereka tidak dapat bersuara dengan lantang untuk menyuarakan segala pergumulan hidup mereka. Lidah mereka terkelu oleh mulut senjata yang siap menerkam siapa saja yang berani menyuarakan ketidakadilan. Alihalih mendapat tanggapan dan perhatian, mereka justru dianggap sebagai pembangkang, anti-Indonesia, bagian dari Kelompok Kriminal Bersenjata (KKB), Operasi Papua Merdeka (OPM), dan sebagainya. ${ }^{21}$ Mirisnya lagi, mulut

19 Hampir 90\% kantong-kantong umat Katolik Keuskupan Timika berada di wilayah-wilayah pedalaman Papua. Berdasarkan data Keuskupan Timika tahun 2019, hanya 11 paroki dari 40 paroki dan 4 kuasi paroki yang berada di pusat perkotaan, sisanya berada di wilayahwilayah pedalaman.

20 Ibid.,142-162.

21 https://jateng.tribunnews.com/2019/09/05/ilc-heboh-saat-pemuda-papua-mamat-alkatiri-beri-pesanuntuk-jokowi, diakses 29 November 2020. 
mereka disumpal oleh dana tertentu yang tidak jarang menghasilkan persoalan baru, ladang uang bagi pihak tertentu, dan kepuasan sesaat sebagai simbol bahwa pemerintah sungguh memperhatikan masyarakatnya. Dana itu sama sekali tidak membangun kehidupan masyarakat setempat, justru merusak moral dan melemahkan daya juang mereka untuk bekerja dan berusaha. ${ }^{22}$ Oleh karena itu, tidak jarang angka kekerasan, penyakit sosial dan kematian meningkat tajam di berbagai wilayah paroki pedalaman. Jika kualitas pendidikan menjadi seperti ini, maka paroki-paroki akan mengalami kesulitan dalam pengaderan pribadi-pribadi yang tersedia untuk pelayanan paroki kelak. Tidak dapat dipungkiri juga, realitas ini akan membunuh benih panggilan untuk menjadi imam atau pun biarawan-biarawati.

\section{Keterlibatan dan Kehadiran: Imam yang Berdialog}

Keberpihakan imam bagi umat Allah yang tidak berdaya dan menderita mesti diwujudnyatakan dalam tindakan konkret. Oleh karena itu, dibutuhkan suatu bentuk reksa pastoral dalam rancangan visi-misi paroki yang bertolak dari konteks dan keprihatinan hidup umat setempat. Visi-misi tersebut dirumuskan dalam berbagai program yang tepat-guna agar pewartaan dan pelayanan pastoral sungguh menyentuh realitas hidup, budaya, dan pergumulan komunitas umat beriman setempat. Jika visi-misi tidak dirumuskan secara jelas, maka pelayanan pastoral imam akan menjadi salah sasaran atau mungkin dapat dimanfaatkan oleh pihak yang tidak bertanggung jawab. Sama seperti Sang Guru, seorang imam juga sebaiknya mengutamakan pemberitaan pembebasan bagi mereka yang terbelenggu oleh penindasan dan ketidakadilan ( $b d k$. Luk 4:19). Untuk menghadapi berbagai persoalan di Keuskupan Timika, seorang imam membutuhkan semangat dialog dan berusaha bekerja sama dengan berbagai pihak. Tentu tidak mudah menghadapi persoalan sosial di tengah masyarakat tanpa suatu kerja sama dengan pihak lain. Pihak lain yang dimaksudkan adalah pemerintah, LSM terkait, para kepala suku, tokoh pemuda, dan para tokoh agama lainnya. Kiranya upaya dialog ini dapat diwujudkan agar persoalan sosial yang besar tidak menjadi beban pribadi semata. Dengan demikian, persoalan yang sangat nyata, seperti ketidakadilan, rasisme, kemiskinan, kelaparan, kasus-kasus kriminal, premanisme, dan kerusuhan dapat ditanggulangi secara bersama. Dalam hal ini, dialog merupakan langkah yang taktis dalam menghadapi berbagai realitas sosial yang begitu kompleks.

Tidak hanya ditantang oleh medan dan situasi kehidupan di medan misi, imam di Keuskupan Timika dihadapkan juga oleh situasi kebudayaan dan agama-agama. Berkaca pada kenyataan komposisi umat di ladang pastoral

22 https://regional.kompas.com/read/2020/01/09/15024371/polda-papua-tangani-5-kasus-korupsi-danadesa-dengan-kerugian-negara-rp-4, diakses 29 November 2020. 
Keuskupan Timika yang terdiri dari berbagai agama dan budaya, seorang imam juga sebaiknya memiliki sikap batin yang tidak mengarah pada eksklusivisme dan inklusivisme pribadi. Ia menjadi rasul untuk semua agama dan budaya di mana ia diutus. Panggilan imamat menuntutnya untuk menjadi orang yang penuh risiko, sama seperti para rasul dan jemaat Kristiani perdana yang terdorong oleh Roh Kudus, memancarkan diri mereka, keluar dari Senakel, kemudian pergi keluar lingkungan Yahudi menuju wilayah orang kafir.

Tentu saja, mewujudkan hal ini tidak mudah. Ia mesti keluar dari dalam kebudayaan asalnya dan membuka diri untuk berdialog dengan budaya dan agama lain. Ia terbuka pada dialog interreligi dan multikultural. Inilah jalan yang tepat agar ia tidak terjebak dalam eksklusivisme dan inklusivisme budaya dan agama apalagi menolak budaya setempat. Tentu saja hal ini merupakan perilaku yang menyakiti umat yang ia jumpai di medan pastoral. Oleh karena itu, Raymundus Sudhiarsa memberikan penekanan bahwa Gereja pada hakikatnya merupakan komunitas beriman multikultural. Pluralis religiuskultural ini merupakan salah satu karakter menonjol dari wajah Gereja. Pertama-tama dan terutama karena iman Kristiani memang merupakan iman lintas budaya. Iman ini selalu bisa lahir kembali dalam budaya mana pun di dunia. Kemampuan inkulturasi dan inkarnasi ini merupakan keniscayaan historis yang sekaligus menegaskan betapa besar dan indahnya hakikat iman itu, yakni rencana Allah, Sang Pencipta bagi manusia. ${ }^{23}$

Untuk sampai pada taraf itu, seorang imam mesti terus melatih dirinya untuk peka terhadap tanda-tanda zaman yang hadir di dalam realitas sosial. Ia mesti keluar dari ego pribadi, tidak berpaut pada diri sendiri dan kepentingan pribadi. Motivasi awal ini harus terus dimurnikan dengan spiritualitas imamat yang ia hidupi dengan kedekatannya dengan Tuhan. Jika motivasinya tidak dimurnikan, maka suatu saat imam akan terjatuh pada tawaran dunia yang menggiurkan. Ia diajak untuk terus mengadakan refleksi, evaluasi diri, ber-discernment, dan bertekun dalam ekaristi dan doa pribadi. Jalan ini tidak hanya memurnikan motivasi, namun juga senjata yang ampuh untuk menilai pikiran, perkataan dan tindakan serta perjuangannya di tengah ladang misi yang dipercayakan kepadanya. Dengan demikian, dalam menghidupi panggilannya, ia tidak hanya berkutat pada pengetahuan indrawi dan akal budi semata, namun juga terdorong oleh hubungan yang total dengan Allah yang memanggilnya untuk melayani ciptaan-Nya yang lain. $\mathrm{Hal}$ ini adalah bagian dari revolusi batin yang total untuk berjuang melawan realitas yang tidak adil dan benar.

23 Raymundus Sudhiarsa, "Membangun Masyarakat Multikultural dalam Terang Iman," dalam Kearifan Sosial Lintas Budaya: SVD Surya Kencana Merespon Misi Gereja, ed. Raymundus Sudhiarsa (Yogyakarta: Lamalera, 2008), 81. 


\section{Pastoral Keluarga Suatu Alternatif}

Keluarga merupakan tempat katekese awal sebab Tuhan secara unik dapat hadir dalam dinamika kehidupan setiap pribadi, dalam keluarga. Peran serta orang tua dalam mendidik anak-anak dapat terlihat dengan jelas dalam keluarga. Situasi di dalam rumah milik keluarga-keluarga Katolik dibangun sedemikian rupa agar proses didikan pengetahuan serta praktik katolisitas dapat menjadi habitus setiap anggota keluarga. ${ }^{24}$

Berhadapan dengan situasi konteks paroki di Keuskupan Timika, keluarga memiliki peran yang sangat vital. Keluarga adalah corong keselamatan yang berhimpun dalam paroki. Dalam konteks ini, keluarga diajak untuk menjadi "tungku api" kehidupan yang nyata. Keluarga menjadi tempat setiap orang menemukan kehangatan diri. Di dalam keluarga ada cinta, harapan, dan kehidupan. Dalam suasana kehangatan itulah seorang anak diasuh, diasih, dibimbing, dan dibina menjadi pribadi yang bermartabat dan luhur di hadapan Tuhan dan sesama. Di dalam kehangatan keluarga itulah Injil diwartakan oleh orang tua dengan ajaran Kitab Suci dan suri teladan yang luhur. Kehangatan keluarga juga memungkinkan proses pewarisan budaya dapat terwujud secara penuh. Dengan demikian, sang anak mendapat perlengkapan budaya yang penting untuk membentengi dirinya dari pengaruh budaya materialisme, hedonisme, dan sekularisme di tengah dunia. Dalam hal ini pastor paroki memiliki peran yang sangat penting untuk meneguhkan, menyapa, dan hadir dalam keluarga Kristiani. Pastor paroki diharapkan untuk tidak "alergi" terhadap praktik kunjungan umat. Dengan cara ini, umat senantiasa merasa disapa dan tidak beralih dan berpindah pada "ladang" lain.

Pada akhirnya, keluarga mesti menjadi saksi Kristus di tengah dunia. Orang tua tidak sekadar menyampaikan Injil kepada anak-anak mereka, melainkan dari anak-anak sendiri, mereka dapat menerima Injil itu juga, dalam bentuk penghayatan mereka yang mendalam..$^{25}$ Dalam situasi zaman seperti ini, keluarga dituntut untuk berani memberi kesaksian akan imannya dan kesetiaannya dalam hidup perkawinan dan keluarga. ${ }^{26}$ Jika hal ini dapat terwujud, maka imam sudah menjalankan sebagian tanggung jawabnya dengan baik. Ia telah membuktikan bahwa keteladanan hidupnya dapat menjadi inspirasi bagi keluarga untuk bertumbuh dalam iman dan menjadi pewarta iman bagi dunia dan sesamanya yang lain.

24 Bdk. Op.Cit., Robert J. Hater, 113.

25 Edison R.L. Tinambunan, "Kelahiran Katekese”, Pembaharuan Gereja Melalui Katekese: Superfisialisme, Aktivisme, Fundamentalisme dan Spiritualisme Tantangan Katekese Dewasa ini, Eds. Ropert Pius Manik, Prosiding Seri Filsafat Teologi (2018), 58.

26 Al. Bagus Irawan, Gereja Misioner yang Diterjang Sabda Allah, (Yogyakarta: Kanisius, 2011), 246-247. 


\section{Simpulan}

Seorang imam adalah in Persona Christi atau alter Kristus. Ia dipanggil oleh Kristus untuk hidup seperti Kristus sendiri untuk menguduskan dunia melalui karya-karyanya. Hidup seperti Kristus berarti memberikan diri secara total dalam tugas dan pelayanan yang dipercayakan kepadanya. Totalitas pelayanan ini terwujud dalam karya-karya pastoral yang tidak mudah di tengah dunia saat ini. Ia ditantang oleh realitas dan situasi dunia yang tidak mudah. Dalam konteks Keuskupan Timika, para imam ditantang oleh persoalan-persoalan yang kompleks, di mana dalam kehidupan pelayanannya, para imam diajak untuk terlibat dan melebur dalam situasi-situasi hidup umat yang dilayani. Dengan spiritualitas imamat yang ia hayati setiap harinya, ia dibantu untuk menemukan Kristus dalam diri orang-orang yang tidak berdaya, situasi hidup yang mencekam, dan tantangan budaya yang kompleks di Keuskupan Timika. Oleh karena itu, dalam hidup pelayanannya seharihari, ia diharapkan untuk mewujudkan spirit pelayanan Yesus Kristus dalam bentukketerlibatan yang dedikatif, kehadiran yang menyejukkan, masukdalampergumulanhidupkeluarga, dan beraniuntukberdialogdengansiapa pun di tengahtantanganmedan pastoral diKeuskupan Timika.Dengan demikian, seorang imam dapat mewujudkan spirit pelayanan Yesus Kristus di tengah dunia dan menjadi corong keselamatan yang berharga bagi umat di tengah dunia ini.

\section{KEPUSTAKAAN}

\section{Gerejawi}

Dokumen Konsili Vatikan II. Dekrit Pelayanan dan Kehidupan Para Imam Presbyterorum Ordinis. Konsili Ekumenis Vatikan II, penerjemah oleh R. Hardawiryana. Jakarta: OBOR, 2009.

Priest Pastor and Leader of the Parish Community (2002).

Yohanes Paulus II. Pastores Dabo Vobis. Penerjemah oleh R. Hardawiryana. Jakarta: Dokpen KWI, 1992.

\section{Umum}

Hater, Robert J. The Catholic Parish: Hope for a Changing World. New Jersey: Paulist Press, 2004.

Irawan, Al. Bagus. Gereja Misioner yang Diterjang Sabda Allah. Yogyakarta: Kanisius, 2011.

Kira, Biru. Berlayar ke Timur. Yogyakarta: Kanisius, 2014.

Kristianto, A. Eddy. Menjadi Gereja yang Berjalan Bersama Papua. Jakarta: OBOR, 2017.

Sanjaya, Indra V. (eds.). Mozaik Gereja Katolik Indonesia Tahun Pasca Konsili Vatikan II. Yogyakarta: Kanisius, 2013. 
Sudhiarsa, Raymundus. 2008. Membangun Masyarakat Multikultural dalam Terang Iman. dalam Raymundus Sudhiarsa (ed.), Kearifan Sosial Lintas Budaya: SVD Surya Kencana Merespon Misi Gereja. Yogyakarta: Lamalera.

Tinambunan, Edison R.L. "Kelahiran Katekese", Pembaharuan Gereja Melalui Katekese: Superfisialisme, Aktivisme, Fundamentalisme dan Spiritualisme Tantangan Katekese Dewasa ini. Eds. Ropert Pius Manik, Prosiding Seri Filsafat Teologi (2018), 57-71.

Tinambunan, Edison R.L. "Quo Vadis Imam - Imamat Revolusi Industri 4.0", Siapakah Manusia; Siapakah Allah. Vol. 29, 28, (Oktober 2019).

\section{Internet}

https://papua.bps.go.id/dynamictable/2018/05/16/134/jumlah-penduduk-hasilproyeksi-menurut-jenis-kelamin-dan-kabupaten-kota-di-provinsi-papua-20102020.html, diakses 28 November 2020.

https://jateng.tribunnews.com/2019/09/05/ilc-heboh-saat-pemuda-papua-mamatalkatiri-beri-pesan-untuk-jokowi, diakses 29 November 2020.

https://regional.kompas.com/read/2020/01/09/15024371/polda-papua-tangani-5kasus-korupsi-dana-desa-dengan-kerugian-negara-rp-4, diakses 29 November 2020 . 